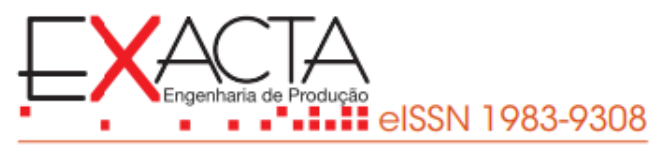

\title{
MODELO DE PROCESSO DE INOVAÇÃO ABERTA NO FORMATO DE UMA INDICAÇÃO GEOGRÁFICA: O CASO DO AGLOMERADO DA PEQUENA INDÚSTRIA DE LEITE NO SEMIÁRIDO DE PERNAMBUCO
}

\author{
MODEL OF OPEN INNOVATION PROCESS IN FORMAT OF A GEOGRAPHICAL \\ INDICATION: THE CASE OF THE SMALL MILK INDUSTRY IN THE PERNAMBUCO \\ SEMI-ARID
}

Recebido em: 16 fev. 2020

Aprovado em: 04 ago. 2020

Versão do autor aceita publicada online: 04 ago. 2020

Publicado online: 18 jun. 2021

\section{Como citar esse artigo - American Psychological Association (APA):}

Roma, S. de C., Cavalcanti, A. M., \& Silva, A. M. (2021, out./dez.). Modelo de processo de inovação aberta no formato de uma indicação geográfica: o caso do aglomerado da pequena indústria de leite no semiárido de Pernambuco. Exacta. 19(4), 933-953. https://doi.org/10.5585/exactaep.2021.16613.

Submeta seu artigo para este periódico $\beta$

Dados Crossmark 


\title{
MODELO DE PROCESSO DE INOVAÇÃO ABERTA NO FORMATO DE UMA INDICAÇÃO GEOGRÁFICA: O CASO DO AGLOMERADO DA PEQUENA INDÚSTRIA DE LEITE NO SEMIÁRIDO DE PERNAMBUCO
}

\author{
MODEL OF OPEN INNOVATION PROCESS IN FORMAT OF A GEOGRAPHICAL \\ INDICATION: THE CASE OF THE SMALL MILK INDUSTRY IN THE PERNAMBUCO \\ SEMI-ARID
}

(D) Suely de Carvalho Roma ${ }^{1}$
(i) André Marques Cavalcanti ${ }^{2}$
iD Auristela Maria da Silva ${ }^{3}$

${ }^{1}$ Mestre

Universidade Federal Rural de Pernambuco - UFRPE. Recife, Pernambuco - Brasil.

suely.roma@yahoo.com.br

2 Doutor

Universidade Federal de Pernambuco - UFPE.

Recife, Pernambuco - Brasil.

andremarques2008@gmail.com

${ }^{3}$ Mestre

Universidade Federal Rural de Pernambuco - UFRPE. Recife, Pernambuco - Brasil.

auristela.msilva@gmail.com

Recebido em: 16 fev. 2020

Aprovado em: 04 ago. 2020
Resumo: A economia da região semiárida do nordeste brasileiro historicamente sempre esteve ligada ao leite bovino. Este estudo tem por objetivo analisar se no modelo de gestão adotada no aglomerado da pequena indústria do leite há processo de inovação. Para atingir esse objetivo, foi realizada uma pesquisa de campo a partir de entrevista estruturada com base nos requisitos do modelo teórico de inovação aberta. Dentre os achados deste estudo, os pesquisados mostram-se limitados e passivos às técnicas que já existem e dominam, como também aos conceitos e ações que viabilizem a adoção de um perfil inovador. Propor um modelo de processo de inovação aberta como fator estratégico de desenvolvimento deste setor é uma possibilidade que está alinhada com a condição das empresas investigadas.

Palavras chave: Leite bovino. Modelo de Gestão. Inovação aberta.

Abstract: The economy of the semiarid region of northeastern Brazil has historically been linked to bovine milk. This study aims to analyze if the management model adopted in the cluster of the small dairy industry has an innovation process. To achieve this goal, a field research was conducted from a structured interview based on the requirements of the open innovation theoretical model. Among the findings of this study, the respondents are limited and passive to the techniques that already exist and dominate, as well as the concepts and actions that enable the adoption of an innovative profile. Proposing an open innovation process model as a strategic factor for the development of this sector is a possibility that is aligned with the condition of the investigated companies.

Keywords: Bovine milk. Management model. Open innovation. 
1 Introdução

Inovação tem conceitos variados, sendo um conceito bem difundido aquele que afirma que inovação é a exploração de novas ideias. Entretanto, não é incomum observar-se que as pessoas frequentemente confundem inovação e processos de inovação, com melhoria contínua e processos relacionados a esse tema. Para que uma inovação seja vista como tal é necessário que tenha causado um impacto significativo, pois melhorias contínuas, normalmente, não são capazes de criar vantagens competitivas de médio e longo prazo.

Reconhecendo, portanto, que a inovação tem um compromisso com um impacto significativo, pode-se afirmar que são objetivos focais da inovação: a inovação de produto que consiste em modificações no produto de forma que provoque uma mudança de percepção deste pelos consumidores; inovação de processo que consiste em mudanças no processo de produção do produto ou serviço e que, não necessariamente, gere impacto no produto final. Seu foco é trazer benefícios no processo de produção, gerando aumento de produtividade e redução de custos. Observa-se que os objetivos da inovação têm como foco tornar os produtos mais competitivos em um cenário de competição em um mercado globalizado

A inovação de modelo de negócio considera mudanças na forma como o produto ou serviço vem a ser oferecido ao mercado, que não implica necessariamente em mudanças no produto, ou processo de produção, mas na forma como ele é levado ao mercado. Nesse sentido as empresas que, por vezes, fazem parte de uma mesma região geográfica buscam identificar interesses comuns para competirem no mercado. Optando assim, por estabelecerem processos de inovação aberta para que esses produtos e serviços produzidos e ofertados nessa região sejam reconhecidos como oriundos de uma Indicação Geográfica (IG).

Considerando a gestão do processo de inovação como um fator importante no mundo econômico, optou-se nesta pesquisa por entender como a inovação se estabelece no mercado do aglomerado da pequena indústria de leite bovino na região do semiárido do nordeste brasileiro, especificamente utilizando como amostra o Estado de Pernambuco. Além disso, em virtude da identificação de características únicas e comuns aos processos, produtos, serviços e aspectos culturais associados entende-se a possibilidade do estabelecimento de uma Indicação Geográfica para a indústria do leite instalada nessa região.

Tendo em vista que a cadeia produtiva do leite é relevante no setor socioeconômico da região nordeste e uma das atividades mais presentes no semiárido brasileiro, com a participação do Estado de Pernambuco de 21,9\% na produção total nesta região (Serviço Brasileiro de Apoio às Micro e Pequenas Empresas [SEBRAE], 2020). Entretanto, este percentual ainda está aquém da real potencialidade deste setor produtivo. Atualmente, prevalece na região micro e pequenos empreendedores, que apesar de 
suas iniciativas, sinalizam dificuldades com os aspectos da gestão quando considerado o contexto da competitividade em um mercado globalizado. Desta forma, o presente estudo apresenta como proposta estabelecer um modelo de inovação aberta que permita formar uma relação mais produtiva e de qualidade, do insumo leite bovino, para auferirem melhores resultados a partir de um articulador de inovação estabelecido entre as partes interessadas nesse setor produtivo caracterizando assim, uma Indicação Geográfica (IG). Passando por um processo de identificação dessas características comuns em um interesse coletivo concretizando-se através da inovação aberta para estabelecer a IG. Para isso foi realizada uma pesquisa do tipo exploratória documental combinada com um survey, tomando-se uma amostra por conveniência de empresas que compõem um aglomerado na região do semiárido do Estado de Pernambuco como ponto focal de uma possível aplicação do modelo proposto.

Para subsidiar esta análise, foi necessário identificar se no modelo de gestão adotada pelo aglomerado da pequena indústria de leite da região do semiárido do Estado de Pernambuco há processos de inovação, quais os mecanismos, instrumentos ou modelos adotados na gestão, e quais as ações de relevância para o êxito na produção.

\section{Referencial teórico}

Neste capítulo são apresentadas definições de modelos de gestão de inovação aberta, indicações geográficas e o perfil da indústria de leite na região do semiárido do Estado de Pernambuco.

\subsection{Modelos de gestão de inovação aberta}

Rothwell (1994) avalia os modelos de gestão da inovação desde a década de 1960 e observa um padrão de evolução, que parte de modelos lineares para modelos interativos. Os modelos de primeira e segunda geração seriam chamados de lineares simples, onde a correspondência aos processos industriais é perceptível, pois na primeira geração predominava a inovação empurrada pela tecnologia e na segunda geração a inovação puxada pelo mercado. No entanto, os modelos de terceira geração reconhecem combinações de tecnologia ou mercado para iniciar o processo, e acrescenta à anterior linearidade de retorno entre as fases. Já na quarta geração os modelos beneficiariam uma perspectiva de atividades paralelas e auxiliadas por alianças e parcerias. Diferentemente da quinta geração, a inovação seria vista como um processo contínuo, promovendo a integração de uma rede abrangente de relações e reações customizadas.

Berkhout, Hartmann, Duin e Ortt (2006) reconhecem fundamentalmente três gerações e sugerem uma quarta geração com propriedades semelhantes à quinta geração de Rothwell (1994), porém defendem numa última análise que a inovação seja mais bem delineada por um sistema circular e não por uma cadeia com início e fim definidos. 
O modelo clássico de Clark e Wheelwright (1992) expõe processo de concepção, refinamento e seleção ideias de produtos num formato de funil, caracterizado pela seletividade que diversas ideias de produto são tratadas até resultarem em uma quantidade muito menor de produtos lançados no mercado, filtrando desta forma os projetos de pesquisa e desenvolvimento também pelo problema de alocação de recursos, por dificilmente haver tempo e recursos suficientes para todos os projetos de inovação. O modelo gráfico é eficaz em comunicar que, dentre as várias possibilidades de desenvolvimento, poucas de fato alcançarão espaço no portfólio de produtos correntes de uma organização (Figura 1).

\section{Figura 1}

Funil de desenvolvimento

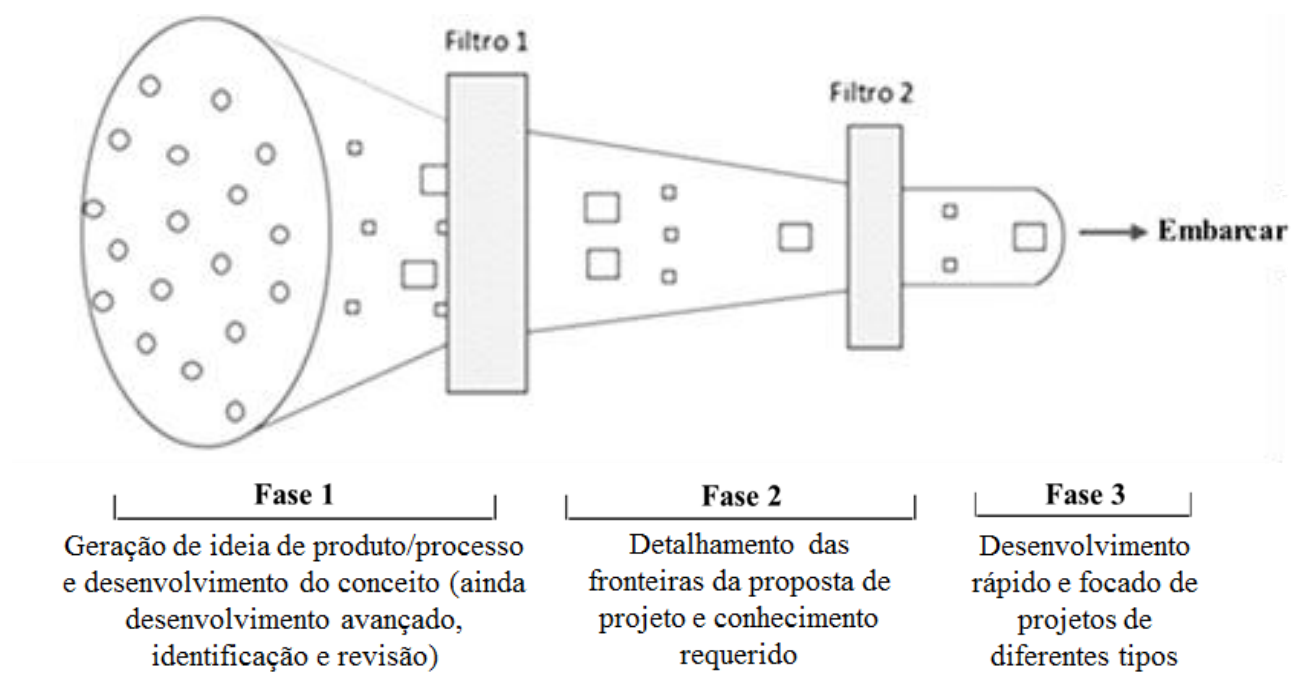

Fonte: Clark e Wheelwright (1992).

Cooper (1993) apresenta seu modelo tendo como característica essencial o reconhecimento da inovação tecnológica como processo centralizado no desenvolvimento de novos produtos. 0 reconhecimento deste modelo acontece por condições inerentes às organizações, como as relações interfuncionais, que são necessárias em cada fase do processo, desde a ligação com o mercado até a alta gestão da empresa. Cooper (1994) ainda defende que o processo de desenvolvimento de novos produtos seja redesenhado em estágios previamente definidos, sendo estabelecido para cada um atividades interligadas e paralelas.

Em seguida, o modelo recebe novo aspecto com variação dentre os estágios (Cooper, 1994), evoluindo da segunda geração para terceira, ganhando em seguida condição escalável, na qual mostram-se possibilidades divergentes e complexas em concepções de ideação numa organização, alegando, no entanto, que o seu sistema é essencialmente um processo de negócio (Cooper, 2008). 
Conforme Chesbrough (2003) a expressão inovação aberta ou open innovation refere-se às várias definições pertinentes à busca de fontes externas de tecnologia e inovação para guiar o desenvolvimento organizacional, desde atividades como geração de spin-offs até licenciamento de patentes não utilizadas. A inovação aberta transformou-se em um novo modelo para organizar a inovação. Parte-se do pressuposto, na inovação aberta, que as ideias externas podem e devem ser usadas pelas empresas, como também as ideias internas e caminhos internos e externos para o mercado, ao passo que procuram avançar em suas inovações. Processos de inovação aberta ajustam as ideias internas e externas, sejam em plataformas, arquiteturas e/ou sistemas. Modelos de negócios são usados nos processos de inovação aberta para definir requisitos para arquiteturas e sistemas. Esses modelos de negócios acessam ideias externas e internas para criar valor, enquanto definem mecanismos internos para reivindicar uma parte desse valor (Chesbrough, 2003).

Chesbrough, Vanhaverbeke e West (2017) entendem a inovação aberta como um processo de inovação distribuído baseado em fluxos de conhecimento propositadamente gerenciados através das fronteiras organizacionais. São dadas ideias sobre como as empresas podem aproveitar fluxos de entrada e saída de conhecimento para melhorar o sucesso da inovação.

Ocorre que a pesquisa sobre inovação aberta se amplia, estendendo-se a diversas áreas, um amplo conjunto de áreas e campos, como os das pequenas e médias empresas, diversidades de indústrias de baixa e alta tecnologia, organizações sem fins lucrativos e políticas públicas.

Segundo West e Bogers (2017), a parte externa da inovação aberta abrange a abertura dos processos de inovação de uma empresa para muitos tipos de contribuições, inclusive contribuições externas. Esse aspecto da inovação aberta ganhou uma maior atenção, tanto na pesquisa acadêmica quanto na prática da indústria. A inovação aberta de dentro para fora exige que as organizações deixem que ideias não utilizadas e subutilizadas saiam da organização para que outras a usem em seus negócios e modelos de negócios. Em contrapartida, a parte externa do modelo é menos explorada e, logo, não tão bem entendida, tanto na pesquisa acadêmica quanto na prática da indústria.

Discorrendo sob o mesmo ponto de vista, conforme o Manual de Oslo (Organização para a Cooperação e Desenvolvimento Econômico [OECD], 2018), inovação aberta denota o fluxo de conhecimento relevante para a inovação através dos limites das organizações individuais, incluindo modelos de negócios baseados em proprietários que usam licenciamento, colaborações, joint ventures, dentre outras condições contratuais ou mercadológicas, para produzir e compartilhar conhecimento. Essa noção de "abertura" não implica necessariamente que o conhecimento seja gratuito ou isento de restrições de uso. As restrições de preço e uso são frequentemente condições-chave para o acesso ao conhecimento.

A estrutura da inovação aberta nos negócios é vista como um processo altamente distribuído, baseado em fluxos de conhecimento gerenciado através dos limites organizacionais, onde o 
conhecimento através das fronteiras das empresas ativas em inovação fornece uma estrutura conceitual e lógica para a medição de tais fluxos e intercâmbios de inovação aberta entre empresas e outros atores no sistema de inovação. Essa estrutura é usada como base para recomendações sobre como medir fluxos de conhecimento de entrada e saída, fontes internas e externas de conhecimento para inovação, parceiros de colaboração de inovação, bem como facilitadores e barreiras aos fluxos de trocas e de conhecimento, como exemplo, quando uma empresa licencia sua tecnologia, patentes ou protótipos para outra empresa (OECD, 2018).

\subsection{Indicações geográficas}

O Acordo sobre Aspectos de Propriedade Intelectual relacionado ao Comércio (TRIPS) define as indicações geográficas (IG) como indicações que identifiquem um produto como originário do território de um país, ou região ou localidade deste território, quando determinada qualidade, reputação ou outra característica do produto seja essencialmente atribuída à sua origem geográfica (Decreto n. 1.355, 1994). No âmbito nacional, a IG é regulamentada pela Lei da Propriedade Industrial no 9.279, de 1996 (Lei n. 9.279, 1996).

De acordo com Lei n. 9.279 (1996), as IG apresentam duas modalidades: a Indicação de Procedência (IP) que, de acordo com o artigo 177, é o "nome geográfico de país, cidade, região ou localidade de seu território, que se tenha tornado conhecido como centro de extração, produção ou fabricação de determinado produto ou de prestação de determinado serviço" e a Denominação de Origem (DO) que, segundo o artigo 178, é o “nome geográfico de país, cidade, região ou localidade de seu território, que designe produto ou serviço cujas qualidades ou características se devam exclusiva ou essencialmente ao meio geográfico, incluídos fatores naturais e humanos".

Para Chimento e Valente (2016), a distinção entre as duas modalidades consiste em que enquanto a IP é uma classificação que depende da reputação local, enfocando o aspecto social, a DO, por sua vez, exige a comprovação de que aspectos naturais e ou humanos podem exercer influência nas características e ou qualidades do produto ou serviço.

O Serviço Brasileiro de Apoio às Micro e Pequenas Empresas traz as seguintes definições para IP e DO:

Indicação de Procedência: valoriza a tradição produzida e o reconhecimento público de um produto que é produzido em uma determinada região e que apresenta uma qualidade diferenciada. Consequentemente, a área em que se encontra tal produto é reconhecida pela produção, extração ou beneficiamento. O objetivo maior do reconhecimento através da Indicação de Procedência é a de proteger a relação histórica entre o produto e sua reputação, relacionada à origem geográfica específica (SEBRAE, 2014). 
Denominação de Origem: essa forma de proteção é destinada onde as características daquele território agregam um diferencial ao produto. A DO define que uma determinada área tenha um produto cujas qualidades sofram influência exclusiva ou essencial por causa das características daquele lugar, incluídos fatores naturais e humanos. São valorizadas as peculiaridades daquela região, que devem afetar beneficamente o resultado final do produto, de forma identificável, constante e mensurável (SEBRAE, 2014).

Observa-se, a partir das definições apresentadas, que os requisitos de notoriedade, reputação, características específicas e de qualidade são intrínsecos às IG que sugerem o potencial para o reconhecimento do registro. Ressalta-se que distinguir produtos e serviços por meio de IG propicia a promoção da região, a agregação de valor e a comunicação ao mercado quanto aos atributos de qualidade de produtos e ou serviços ofertados, e ainda promove tipicidade, tradição e patrimônio cultural (Cerdan, Brunch, \& Lima da Silva, 2014).

De acordo com Sá, Novais, Silva Nogueira e Silva (2016), o selo de origem proporciona benefícios para o consumidor, para o produtor e para toda região, tais como: garantia de um produto único, com diferenciais de qualidade e sustentabilidade, estimulo ao desenvolvimento da governança local, promoção do turismo e das atividades culturais regionais. Entretanto, Bezerra e Nascimento Júnior (2015) destacam que, para a identificação do potencial de uma IG é necessário avaliar, no mínimo, três aspectos: se o produto ou alimento tem seu nome associado à região geográfica; se este nome conquistou notoriedade por seus atributos advinda de características regionais ou ocorre da tradição dos produtores.

As indicações geográficas vêm sendo utilizadas como importante ferramenta de proteção de nomes geográficos vinculados a produtos típicos de territórios brasileiros, favorecendo o desenvolvimento local e econômico destas regiões (SEBRAE, 2014).

Diversos produtos agroalimentares se destacam pela sua qualidade ou reputação devido principalmente ao local de produção, podendo estar associadas a aspectos culturais, fatores naturais ou humanos. Exemplos notáveis de produtos agroalimentares associados à sua origem incluem: a cachaça de Paraty do Rio de Janeiro, o queijo da Serra da Canastra de Minas Gerais e os doces de Pelotas do Rio Grande do Sul. No cenário nacional, até junho de 2018, foram concedidas pelo INPI o total de 67 Indicações Geográficas, sendo 56 nacionais e 08 estrangeiras procedentes de países como França, Portugal e Itália. Neste universo, destacam-se a concessão de Indicações de Procedência com um total de quarenta e nove registros, enquanto as Denominações de Origem apresentam o número de dezoito registros, dos quais dez são estrangeiras (Instituto Nacional de Propriedade Industrial [INPI], 2018). Dos registros concedidos, encontram-se uma gama de produtos, destacando-se os segmentos de alimentos e bebidas. A intensificação nos pedidos de IG para estes segmentos acompanha a tendência de crescimento econômico, pois, de acordo com a Associação Brasileira das Indústrias da Alimentação, no 
ano de 2017, a indústria de alimentação cresceu 4,6\%, atingindo a cifra de $\mathrm{R} \$ 642,6$ bilhões, da qual 81\% refere-se ao segmento de alimentos e 19\% de bebidas (Associação Brasileira das Indústrias da Alimentação [ABIA], 2017). Dentre as Indicações geográficas reconhecidas, destacam-se produtos e bebidas como vinhos, café, queijos, mel, entre outros. Todavia, o registro de indicação geográfica para o queijo de coalho artesanais ainda é incipiente, produto existente no mercado que se destaca pela sua importância econômica, atrelada a tradição na região Nordeste do Brasil, a exemplo da produção existente na região do Semiárido de Pernambuco.

\subsection{Indústria do leite na região do semiárido do Estado de Pernambuco}

A pecuária se desenvolveu na região com a chegada da palma forrageira no século XIX. Essa planta é o principal alimento do gado no período da seca. A palma tornou-se a base da criação e manutenção do gado dos criadores do Nordeste, e voltou a ser cultivada em larga escala pelos criadores das bacias leiteiras, principalmente em Pernambuco e Alagoas. Estima-se existirem hoje, no Nordeste, aproximadamente 500.000 hectares cultivados, constituindo-se como uma das principais forrageiras para o gado leiteiro (Paquereau, Machado, \& Carvalho, 2016).

Além da preocupação nutricional do rebanho bovino, alguns produtores, juntamente com autoridades do Estado de Pernambuco ligadas à agropecuária, tiveram, desde o início do século XX, a preocupação de cuidar melhor do seu rebanho no que diz respeito à sanidade do animal, a fim de obtenção de um produto de melhor qualidade em se tratando do leite e seus derivados, bem como da carne. Essa preocupação, com a saúde do gado, tornou-se evidente quando se tratou de vacinar o animal contra qualquer tipo de doença. O objetivo era torna-se mais competitivo no mercado, tendo como meta produzir leite e carne de boa qualidade (Paquereau et al., 2016).

Paquereau et al. (2016) dizem que a condição necessária para uma boa produção na região são as altitudes, que variam entre os 600 e 1.000 metros, de maneira que a amplitude térmica diurna é relativamente elevada, o que propicia melhor adaptação do gado europeu, na condição de bom produtor de leite. Nessas localidades, há a predominância do gado mestiço de Holandês como a raça Zebu, com destaque para a raça Gir, além da presença maior do animal puro sangue da raça holandesa. Constatam-se, portanto, nessa área, as médias mais altas da produção leiteira do Estado e os períodos mais amplos de lactação.

A região, que constitui o cenário mais específico da pesquisa, num espaço geográfico e temático da pecuária e de seus derivados, foi delimitada nos municípios de Venturosa e Pedra, permitindo o encadeamento com o universo econômico de um insumo vital de uma cadeia produtiva, o leite bovino.

Segundo o SEBRAE (2013), a cadeia produtiva do leite apresenta grande relevância socioeconômica para a região nordeste do Brasil, sendo uma das atividades mais presentes no 
semiárido, e o Estado de Pernambuco ser detentor de uma participação de 21,9\% na produção total desta região. Entretanto, o baixo nível tecnológico aplicado na exploração leiteira e a falta de gestão mais profissionalizada nas propriedades conferem ao segmento produtivo indicadores técnicos aquém das suas reais potencialidades. A produção média por vaca/ano na região é de $817 \mathrm{Kg}$ (Ramos, Costa Borba, Carvalho, \& Xavier, 2018) e a produção por propriedade/dia é de apenas 21,4 litros (Instituto Brasileiro de Geografia e Estatística [IBGE], 2006). Estes indicadores refletem o longo caminho a ser percorrido em busca da eficiência e sustentabilidade da atividade.

Considerando, ainda, o cenário nacional do setor leiteiro, o Ministério da Agricultura, Pecuária e Abastecimento [MAPA] (2019) reconhece que há problemas de concorrência, fortes subsídios e subvenções neste segmento, porém envida esforços entendendo a importância e a sensibilidade deste setor, não somente social, mas econômico para o país. O setor leiteiro trata-se de um dos mais inclusivos do agronegócio, em que pequenas propriedades rurais, com área de até 50 hectares, são responsáveis por $51 \%$ do leite líquido comercializado no campo, ou seja, por mais da metade da produção comercial. No total, cerca de 1,2 milhão de estabelecimentos rurais são dedicados à produção de leite no país.

Medidas mais imediatas, como o antidumping, que torna a concorrência mais leal neste setor, foram indubitavelmente eficazes e decisivas para a rentabilidade e a manutenção dos produtores rurais na atividade (MAPA, 2019).

Promover oportunidades para as pequenas empresas do setor leiteiro nacional é seguramente uma ação necessária, pois reconhecendo que a medida antidumping é temporária, é preciso trabalhar em ações que permitam reestruturar o setor como um todo, ou seja, reorganizar a cadeia produtiva do país, para tornar o segmento mais competitivo (MAPA, 2019).

\section{Metodologia}

Optou-se neste estudo por uma pesquisa de campo, especificamente por um grupo de pequenos produtores de leite bovino do semiárido do Estado de Pernambuco, o que favoreceu um entendimento mais acurado deste segmento, proporcionando inclusive uma visão holística, uma fotografia mais realística do objeto de estudo. Inicialmente essa investigação apresenta um caráter exploratório, sendo contemplada por uma fase qualitativa com objetivo de constatar elementos essenciais que comprovam que o atual modelo de gestão no aglomerado da pequena indústria de leite bovino na região do semiárido do Estado de Pernambuco constitui impedimento ao desenvolvimento deste setor.

Por ter como objetivo compreender melhor o fenômeno a ser estudado e sugerir uma explicação ao lócus desta pesquisa, a opção por uma investigação empírica aplicável dá observações para construção de uma teoria mais adequada (Hill \& Hill, 2009). 
A pesquisa qualitativa tem como característica a abertura das perguntas, onde rejeita-se toda resposta fechada, dicotômica e fatal, propondo mais do que o esquadrinhamento por análise, busca o aprofundamento por familiaridade, convivência, comunicação (Demo, 2015).

Ainda, segundo Demo (2015), a pesquisa qualitativa, tem sua interpretação sempre regada de imenso toque de subjetividade, porém merece crédito pela profundidade de sua visão e, nesse sentido, a pesquisa qualitativa pode ser mais coerente quando comparada as outras que são tão mais precisas quanto também mais superficiais.

Após fazermos análise dos dados, tal formalização pode ser mais profunda, pois uma diferença importante é que é preciso superar o dado linear e chegar ao não linear porque é garantidamente mais real, onde no linear apanhamos a extensão e no não linear a intensidade do fenômeno e para fazer isso com a profundidade necessária tem-se que trabalhar pequeno grupo, que mesmo, jamais, não sendo representativo de um segmento inteiro, pode ser exemplar (Demo, 2015).

Esta pesquisa, numa segunda fase, possui uma abordagem quantitativa, baseada em estatística descritiva simples, que identifica fatores essenciais percebidos pela pesquisadora, que são comparados com os pré-requisitos do Modelo Teórico de Inovação Aberta, que segundo Gil (2002), traz uma pesquisa descritiva decisiva quanto as suas características de população, fenômeno ou variáveis, bem como suas respectivas relações.

A amostra dos dados foi retirada a partir de 04 pequenos produtores de leite bovino do semiárido do Estado de Pernambuco, sendo representativa no universo pesquisado, aceitando com razoável confiança que as conclusões obtidas possam ser extrapoladas para o universo observado, pois as semelhanças em termos de características entre ambos são relevantes ao estudo. Hill e Hill (2009) destacam ainda que é razoável utilizar um universo com dimensão menor quando se pretende usar análise de dados qualitativa, o que vem a ser a ideia, inicial, deste estudo.

O método escolhido para selecionar a amostra deste estudo foi o de amostragem não probabilística, por conveniência, pois houve facilidade de acesso aos empresários. Por ser o estudo de pequena escala, optou-se por uma amostragem por clusters, onde a partir de amostra aleatória de pequenas indústrias de leite bovino utilizou-se o resultado encontrado, de forma comparativa, em todo o segmento ora estudado, onde foi escolhido inicialmente a relação de produtores, decidido a fração de amostragem ou os produtores que seriam investigados, determinando-se $25 \%$ do universo de 16 empresas que compõe a área geográfica delimitada. Finalizou-se o processo com coleta de dados através de observação direta intensiva, com entrevista e observação direta extensiva, com utilização de formulário, sendo aplicado a todas as empresas que constituíram a amostra alvo.

O ponto de partida para a realização da pesquisa de campo foi um contato oficial, presencial, realizado pela pesquisadora junto a Gerência Geral da Agência de Defesa e Fiscalização Agropecuária do Estado de Pernambuco - ADAGRO, que é uma unidade técnica vinculada à secretaria de agricultura 
e reforma agrária do Estado de Pernambuco e tem como missão, promover e executar a defesa, o controle e a inspeção dos produtos de origem animal e vegetal. A Agência de Defesa e Fiscalização Agropecuária do Estado de Pernambuco [ADAGRO] (2019) garante os requisitos dos insumos e serviços utilizados na agropecuária, a identidade e a segurança higiênico-sanitária e tecnológica dos produtos destinados aos consumidores, servindo, portanto, como instrumento de avaliação da qualidade dos mesmos. A visita à ADAGRO teve como objetivo obter informações sobre o número oficial de pequenos produtores de leite bovino do semiárido do Estado de Pernambuco. Na visita foi recomendado a pesquisadora o comparecimento à Regional da ADAGRO localizada no município de Sanharó, distante $199 \mathrm{~km}$ de Recife.

Em visita a Regional da ADAGRO em Sanharó foi constatada que a mesma não tinha registro oficial sobre o número total de produtores de leite bovino, exceto em cada um dos processos administrativos isoladamente, sendo informada a pesquisadora que existiam oficialmente 16 queijarias artesanais, porém todas essas empresas são produtoras de leite bovino, e especificamente, nos municípios de Pedra e Venturosa, que foram as cidades delimitadas por esta regional como referência para este estudo. Destes 16 produtores estabelecidos nos dois municípios citados da supervisão desta regional, quando consultados previamente, apenas quatro se dispuseram a participar voluntariamente da pesquisa.

O sujeito desta pesquisa é caracterizado como pequeno empresário produtor rural de leite bovino, cuja empresa está localizada no semiárido do Estado de Pernambuco e a amostra foi não probabilística, por conveniência, constituída por quatro empresários que se dispuseram a participar: 03 do município de Pedra e 01 do município de Venturosa.

O Instrumento aplicado para obter os atributos essenciais para esta pesquisa foi uma entrevista estruturada constituída de um roteiro de duas partes: a primeira com 02 perguntas para obter as características da pequena empresa produtora de leite bovino e a segunda constituída de 17 perguntas elaboradas e adaptadas pela pesquisadora com base nos requisitos do Modelo Teórico de Inovação Aberta (Chesbrough, 2003), e que trata do comportamento das variáveis consideradas no questionário e relativas à: análise de mercado, benchmarking, transferência de tecnologia, captação de recursos e parcerias. Para cada pergunta o sujeito pesquisado poderia apresentar uma justificativa, caso desejase. Todas as respostas foram anotadas unicamente pela pesquisadora.

Os dados obtidos de cada entrevista foram analisados através de uma estatística descritiva simples e comparados com os pré-requisitos do Modelo Teórico de Inovação Aberta como apresentado na Tabela 1. 
Tabela 1

Critérios do Modelo Teórico de Inovação Aberta

\begin{tabular}{|c|c|}
\hline Variáveis & Pré-Requisitos \\
\hline \multirow{6}{*}{$\begin{array}{l}\text { 1. Análise de } \\
\text { Mercado }\end{array}$} & 1.1 Faz análise de mercado \\
\hline & 1.2 Realiza pesquisa de mercado \\
\hline & 1.3 Avaliação de desempenho junto aos clientes \\
\hline & $\begin{array}{l}\text { 1.4 Esforço para buscar a melhoria do trabalho a partir da avaliação de } \\
\text { desempenho junto aos clientes }\end{array}$ \\
\hline & 1.5 Atendimento das solicitações dos clientes (flexibilização) \\
\hline & $\begin{array}{l}\text { 1.6 Tem um índice para avaliar o desempenho sobre a qualidade do produto } \\
\text { ou serviço }\end{array}$ \\
\hline 2. Benchmark & 2.1 Faz uso de benchmark \\
\hline \multirow{8}{*}{$\begin{array}{l}\text { 3. Transferência de } \\
\text { Tecnologia }\end{array}$} & 3.1 Tem padronização das suas principais atividades \\
\hline & $\begin{array}{l}\text { 3.2 Tem preocupação em aumentar a mecanização ou automação da } \\
\text { produção }\end{array}$ \\
\hline & 3.3 Faz uso de Transferência de Tecnologia \\
\hline & 3.4 Participação dos colaboradores na busca de melhorias dos processos \\
\hline & 3.5 Realiza capacitação para os profissionais da equipe \\
\hline & 3.6 Tem um modelo sistêmico e contínuo de aprendizagem \\
\hline & 3.7 Tem capacidade interna de absorver e disseminar novas tecnologias \\
\hline & 3.8 Realiza P,D\&I - Pesquisa, Desenvolvimento e Inovação \\
\hline $\begin{array}{l}\text { 4. Captação de } \\
\text { Recursos }\end{array}$ & 4.1 Faz capitação de recursos (FACEPE - BNDES-BNE - CNI, FINEP, etc) \\
\hline 5. Parcerias & $\begin{array}{l}\text { 5.1 Realiza Parcerias (Universidades, Institutos de Pesquisa, EMBRAPA, } \\
\text { Laboratórios de Metrologia, Sistema S, etc) }\end{array}$ \\
\hline
\end{tabular}

Quanto às justificativas apresentadas, foi realizada uma análise do conteúdo das respostas apresentadas. A amostra foi constituída de quatro empresas do aglomerado da pequena indústria de leite bovino da região do semiárido do Estado de Pernambuco, registradas na Regional da ADAGRO em Sanharó, especificamente dos municípios de Pedra e Venturosa.

\section{Resultados}

Esta seção proporciona uma análise a partir dos dados e observações coletados em campo, trazendo de forma legítima a posição repassada pelos entrevistados, desde questões estruturais das empresas até os indicadores dos aspectos que possuem relevância para uma melhor compreensão dos elementos que são requisitos para identificação de gestão da inovação aberta.

Na Figura 2, observamos que em relação ao número de funcionários e produção de leite, a Empresa3, apesar de ter um dos menores números de funcionários, é a que possui a maior produção de leite dentre todas as empresas pesquisadas, fato esse atribuído a preocupação do empresário em manter e aumentar constantemente a mecanização ou automação da sua produção. 
Considerando o Modelo Teórico de Inovação Aberta (Chesbrough, 2003), a Tabela 2 apresenta a posição dos entrevistados quanto aos critérios: mercado, benchmark, transferência de tecnologia, captação de recursos e parcerias, detalhando os requisitos mínimos e necessários para sua caracterização, bem como a posição de cada empresa quanto a sua prática ou realização.

Podemos observar pelos resultados que todas as empresas alegam fazer benchmark, embora a maioria não siga os itens do critério de mercado.

\section{Figura 2}

Caracterização das empresas por número de funcionários e produção de leite

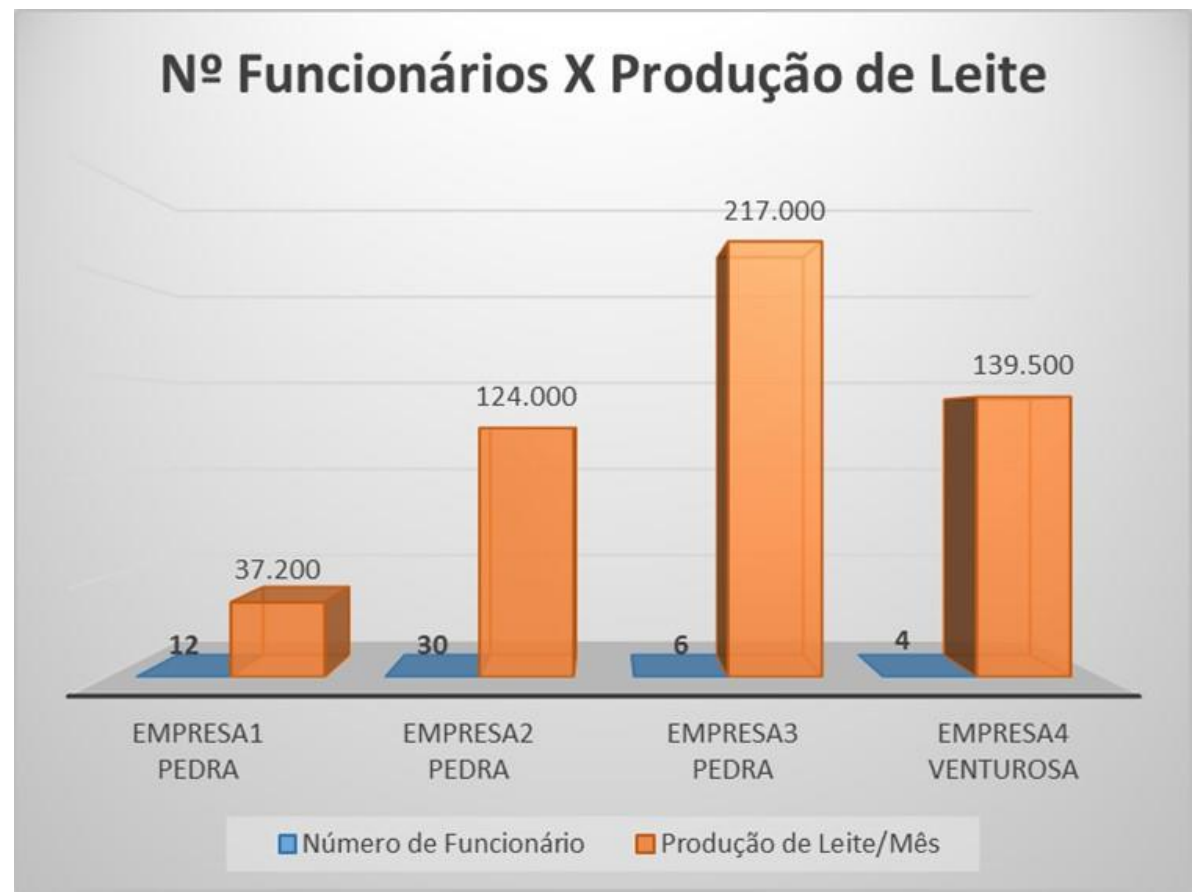

Fonte: Os autores.

Quanto à análise e tratamento dos dados coletados nas respostas do Modelo Teórico de Inovação Aberta, a Tabela 3 mostra que em relação ao retorno da entrevista aplicada, considerando os critérios estabelecidos, a Empresa3 foi a que mais apresentou respostas positivas (70,58\%), ou seja, tal resultado demonstra que de todas as empresas pesquisadas, esta organização é a que mais se aproxima do modelo teórico de inovação aberta. Já a Empresa2, em função da frequência de respostas negativas, ou seja, "Não" (82,35\%), é a que mais se distancia do modelo teórico de inovação aberta. Também há uma ampla percepção do quanto falta para as empresas entenderem conceitos e realizarem ações que de fato viabilizem a adoção de um perfil inovador. 
Tabela 2

Quadro Geral das Respostas as condições iniciais para aplicação da inovação aberta focada em implantar uma IG

\begin{tabular}{|c|c|c|c|c|c|}
\hline \multirow{2}{*}{\multicolumn{2}{|c|}{ Critérios do Modelo Teórico de Inovação Aberta }} & \multicolumn{3}{|c|}{ Pedra } & \multirow{2}{*}{$\begin{array}{l}\text { Venturosa } \\
\text { Empresa4 }\end{array}$} \\
\hline & & Empresa1 & Empresa2 & Empresa3 & \\
\hline \multirow{6}{*}{ Mercado } & Faz análise de mercado & Não & Não & Sim & Não \\
\hline & Realiza pesquisa de mercado & Não & Não & Sim & Não \\
\hline & $\begin{array}{l}\text { Avaliação de desempenho junto } \\
\text { aos clientes }\end{array}$ & Não & Não & Sim & Não \\
\hline & $\begin{array}{l}\text { Esforço para buscar a melhoria do } \\
\text { trabalho a partir da avaliação de } \\
\text { desempenho junto aos clientes }\end{array}$ & Não & Não & Sim & Sim \\
\hline & $\begin{array}{l}\text { Atendimento das solicitações dos } \\
\text { clientes (flexibilização) }\end{array}$ & Sim & Não & Sim & Não \\
\hline & $\begin{array}{l}\text { Tem um índice para avaliar o } \\
\text { desempenho sobre a qualidade do } \\
\text { produto ou serviço }\end{array}$ & Não & Não & Não & Sim \\
\hline \multirow[t]{4}{*}{ Benchmark } & Faz uso de benchmark & Sim & Sim & Sim & Sim \\
\hline & $\begin{array}{l}\text { Tem padronização das suas } \\
\text { principais atividades }\end{array}$ & Não & Não & Não & Sim \\
\hline & $\begin{array}{l}\text { Tem preocupação em aumentar a } \\
\text { mecanização ou automação da } \\
\text { produção }\end{array}$ & Sim & Não & Sim & Sim \\
\hline & $\begin{array}{l}\text { Faz uso de Transferência de } \\
\text { Tecnologia }\end{array}$ & Não & Não & Sim & $\operatorname{Sim}$ \\
\hline \multirow{5}{*}{$\begin{array}{l}\text { Transferência de } \\
\text { Tecnologia }\end{array}$} & $\begin{array}{l}\text { Participação dos colaboradores na } \\
\text { busca de melhorias dos processos }\end{array}$ & Sim & Sim & Sim & Não \\
\hline & $\begin{array}{l}\text { Realiza capacitação para os } \\
\text { profissionais da equipe }\end{array}$ & Não & Não & Não & $\operatorname{Sim}$ \\
\hline & $\begin{array}{l}\text { Tem um modelo sistêmico e } \\
\text { contínuo de aprendizagem }\end{array}$ & Não & Não & Sim & Não \\
\hline & $\begin{array}{l}\text { Tem capacidade interna de } \\
\text { absorver e disseminar novas } \\
\text { tecnologias }\end{array}$ & Sim & Sim & Não & Sim \\
\hline & $\begin{array}{l}\text { Realiza P,D\&I - Pesquisa, } \\
\text { Desenvolvimento e Inovação }\end{array}$ & Não & Não & Não & Não \\
\hline $\begin{array}{l}\text { Captação de } \\
\text { recursos }\end{array}$ & $\begin{array}{l}\text { Faz capitação de recursos } \\
\text { (FACEPE - BNDES-BNE - CNI, } \\
\text { FINEP, etc) }\end{array}$ & Sim & Não & Sim & Não \\
\hline Parcerias & $\begin{array}{l}\text { Realiza Parcerias (Universidades, } \\
\text { Institutos de Pesquisa, EMBRAPA, } \\
\text { Laboratórios de Metrologia, } \\
\text { Sistema S, etc) }\end{array}$ & Não & Não & Sim & Não \\
\hline
\end{tabular}

Fonte: Os autores.

Na Tabela 4 têm-se os resultados do campo de "justificativas", que compõe o instrumento utilizado como roteiro da entrevista e apresenta pontos positivos e negativos registrados pelos entrevistados. Dentre as justificativas apresentadas, "Dar caroço de algodão ao gado" e "higiene do gado" sinalizam uma preocupação positiva, em meio a tantas outras existentes, fundamentais para uma boa produção de leite. 
Um ponto negativo aparente é que todos os sujeitos da pesquisa não dominam os aspectos inerentes à complexidade do mercado. Estão limitados e passivos ao que já existe e dominam, sem sinalizar preocupação ou interesse no processo de evolução de técnicas e, principalmente, das tendências mercadológicas.

\section{Tabela 3}

Análise geral das respostas ao modelo teórico de inovação aberta

\begin{tabular}{|c|c|c|c|c|c|}
\hline \multicolumn{6}{|c|}{ Critérios do Modelo Teórico de Inovação Aberta } \\
\hline $\begin{array}{c}\text { Regional ADAGRO } \\
\text { (Municípios) }\end{array}$ & Empresa & $\begin{array}{c}\mathbf{f n} \\
(\mathbf{n a ̃ o})\end{array}$ & $\mathbf{\%}$ & $\begin{array}{c}\text { fs } \\
\text { (sim) }\end{array}$ & $\mathbf{\%}$ \\
\hline \multirow{3}{*}{ Pedra } & Empresa1 & 11 & 64,7 & 6 & 35,29 \\
\cline { 2 - 6 } & Empresa2 & $\mathbf{1 4}$ & $\mathbf{8 2 , 3 5}$ & 3 & 17,64 \\
\cline { 2 - 6 } & Empresa3 & 5 & 29,41 & $\mathbf{1 2}$ & $\mathbf{7 0 , 5 8}$ \\
\hline Venturosa & Empresa4 & 9 & 52,94 & 8 & 47,05 \\
\hline
\end{tabular}

Fonte: Os autores.

\section{Tabela 4}

Quadro geral das justificativas às respostas ao modelo teórico de inovação aberta.

(continua)

Critérios do Modelo

Teórico de Inovação

$$
\text { Aberta }
$$

Faz análise de mercado

Realiza pesquisa de mercado

Avaliação de

desempenho junto aos

clientes

Esforço para buscar a melhoria do trabalho a partir da avaliação de desempenho junto aos clientes

\section{Atendimento das solicitações dos clientes (flexibilização) \\ Tem um índice para avaliar o desempenho sobre a qualidade do produto ou serviço Faz uso de benchmark Tem padronização das suas principais atividades Tem preocupação em aumentar a}

Pedra Empresa2 Empresa1 Informal wattssapp

Os clientes avaliam

Dar caroço de algodão ao gado, higiene do gado

Inseminação e ordenha mecânica

$$
\begin{gathered}
\text { Informal obrigação, mas não } \\
\text { é formalizado }
\end{gathered}
$$

Em relação a dieta/distribuição
Sim para a Palma
Venturosa

Empresa4

Sim, quem faz é o

dono e usa o PRODEP 
(conclusão)

\begin{tabular}{|c|c|c|c|c|}
\hline $\begin{array}{l}\text { mecanização ou } \\
\text { automação da } \\
\text { produção }\end{array}$ & $\begin{array}{l}\text { de alimento para o } \\
\text { gado }\end{array}$ & & & \\
\hline $\begin{array}{l}\text { Faz uso de } \\
\text { Transferência de } \\
\text { Tecnologia }\end{array}$ & & $\begin{array}{c}\text { Participa de } \\
\text { eventos }\end{array}$ & $\begin{array}{c}\text { Veterinário, } \\
\text { Inseminação, } \\
\text { Gerenciamento (no } \\
\text { campo e } \\
\text { administração) }\end{array}$ & $\begin{array}{l}\text { Hoje menos } \\
\text { via SEBRAE, } \\
\text { ITEP e SENAI }\end{array}$ \\
\hline $\begin{array}{l}\text { Participação dos } \\
\text { colaboradores na } \\
\text { busca de melhorias dos } \\
\text { processos }\end{array}$ & & São ouvidos & & $\begin{array}{c}\text { Participação } \\
\text { tímida }\end{array}$ \\
\hline $\begin{array}{l}\text { Realiza capacitação } \\
\text { para os profissionais da } \\
\text { equipe }\end{array}$ & $\begin{array}{c}\text { Só para } \\
\text { inseminação }\end{array}$ & & $\begin{array}{c}\text { Quando tem } \\
\text { oportunidade para } \\
\text { ordenha e via SEBRAE }\end{array}$ & \\
\hline $\begin{array}{l}\text { Tem um modelo } \\
\text { sistêmico e contínuo } \\
\text { de aprendizagem }\end{array}$ & & $\begin{array}{c}\text { Mão de obra da } \\
\text { região }\end{array}$ & & $\begin{array}{c}\text { Sempre que } \\
\text { entra um } \\
\text { novo } \\
\text { colaborador }\end{array}$ \\
\hline $\begin{array}{l}\text { Tem capacidade } \\
\text { interna de absorver e } \\
\text { disseminar novas } \\
\text { tecnologias }\end{array}$ & & & $\begin{array}{l}\text { Problema de } \\
\text { relacionamento }\end{array}$ & \\
\hline $\begin{array}{l}\text { Realiza P,D\&I - } \\
\text { Pesquisa, } \\
\text { Desenvolvimento e } \\
\text { Inovação }\end{array}$ & & & & \\
\hline $\begin{array}{l}\text { Faz capitação de } \\
\text { recursos (FACEPE - } \\
\text { BNDES-BNE - CNI, } \\
\text { FINEP, etc) }\end{array}$ & & & Bancos e Governo & $\begin{array}{l}\text { Hoje não é } \\
\text { mais viável }\end{array}$ \\
\hline $\begin{array}{l}\text { Realiza Parcerias } \\
\text { (Universidades, } \\
\text { Institutos de Pesquisa, } \\
\text { EMBRAPA, Laboratórios } \\
\text { de Metrologia, Sistema } \\
\text { S, etc) }\end{array}$ & & & $\begin{array}{c}\text { Sistema S e } \\
\text { Laboratórios }\end{array}$ & $\begin{array}{l}\text { Quando } \\
\text { precisa } \\
\text { procura }\end{array}$ \\
\hline
\end{tabular}

Quando analisamos as respostas referentes a cada um dos critérios definidos para o Modelo Teórico de Inovação Aberta (ver Tabela 5) constata-se que apenas "Faz uso de benchmark" é aplicado por todos os sujeitos da pesquisa (100\%). Contudo, o critério "Realiza P,D\&l - Pesquisa, Desenvolvimento e Inovação" não é aplicado por nenhum dos sujeitos da pesquisa, onde esta é uma atividade essencial para uma organização ser caracterizada como inovadora, pois inovação tecnológica e gerencial passaram a representar fator crucial para a competitividade das organizações, tanto as diretamente envolvidas na produção de bens agrícolas, como as pertencentes ao ambiente organizacional desse sistema. Analisando ainda estes critérios, percebe-se que a visão sistêmica trazida pela conceituação do setor agrícola como agronegócio foi um avanço no método científico, apoiando a pesquisa neste segmento da economia. 


\section{Tabela 5}

\section{Análise das respostas por critério do modelo teórico de inovação aberta}

\begin{tabular}{|c|c|c|c|c|}
\hline Critérios do Modelo Teórico de Inovação Aberta & $\begin{array}{l}\text { fn } \\
\text { (não) }\end{array}$ & $\%$ & $\begin{array}{l}\text { fs } \\
\text { (sim) }\end{array}$ & $\%$ \\
\hline Faz análise de mercado & 03 & 75 & 01 & 25 \\
\hline Realiza pesquisa de mercado & 03 & 75 & 01 & 25 \\
\hline Avaliação de desempenho junto aos clientes & 03 & 75 & 01 & 25 \\
\hline $\begin{array}{l}\text { Esforço para buscar a melhoria do trabalho a partir da avaliação de desempenho junto } \\
\text { aos clientes }\end{array}$ & 02 & 50 & 02 & 50 \\
\hline Atendimento das solicitações dos clientes (flexibilização) & 02 & 50 & 02 & 50 \\
\hline Tem um índice para avaliar o desempenho sobre a qualidade do produto ou serviço & 03 & 75 & 01 & 25 \\
\hline Faz uso de benchmark & 0 & 0 & 04 & 100 \\
\hline Tem padronização das suas principais atividades & 03 & 75 & 01 & 25 \\
\hline Tem preocupação em aumentar a mecanização ou automação da produção & 01 & 25 & 01 & 25 \\
\hline Faz uso de Transferência de Tecnologia & 02 & 50 & 02 & 50 \\
\hline Participação dos colaboradores na busca de melhorias dos processos & 01 & 25 & 03 & 75 \\
\hline Realiza capacitação para os profissionais da equipe & 03 & 75 & 01 & 25 \\
\hline Tem um modelo sistêmico e contínuo de aprendizagem & 03 & 75 & 01 & 25 \\
\hline Tem capacidade interna de absorver e disseminar novas tecnologias & 01 & 25 & 03 & 75 \\
\hline Realiza P,D\&I - Pesquisa, Desenvolvimento e Inovação & 04 & 100 & 0 & 0 \\
\hline Faz capitação de recursos (FACEPE - BNDES-BNE - CNI, FINEP, etc) & 02 & 50 & 02 & 50 \\
\hline $\begin{array}{l}\text { Realiza Parcerias (Universidades, Institutos de Pesquisa, EMBRAPA, Laboratórios de } \\
\text { Metrologia, Sistema S, etc) }\end{array}$ & 03 & 75 & 01 & 25 \\
\hline
\end{tabular}

Fonte: Os autores.

Essas atividades com relacionamentos dinâmicos e complexos representam desafios significativos, mas não intransponíveis, para a medição da inovação. Definições de atividades de inovação, bem como inovação propriamente dita, são necessárias para viabilizar medidas para a inovação e seus resultados econômicos subsequentes. Os dados sobre inovação são relevantes para gestores e stakeholders de organizações privadas e públicas, acadêmicos e usuários de políticas. Analistas de políticas e governos em todo o mundo buscam promover a inovação, porque é um fator essencial de produtividade, crescimento econômico e bem-estar. Além disso, as políticas exigem um entendimento empiricamente fundamentado de como a inovação funciona para apoiar mudanças econômicas e sociais que possam enfrentar os desafios domésticos e globais. Esses desafios incluem, especialmente, mudanças demográficas e a necessidade de segurança alimentar, além de muitos outros obstáculos ao bem-estar (OECD, 2018).

Ainda nesse processo de estabelecer as condições iniciais para definição da instalação de uma IG deve-se considerar a identificação das características regionais que a diferencia das demais regiões. Nesse sentido deve-se verificar as características do leite que diferenciam-se o do leite produzido em outras regiões. Isso devido aos seguintes aspectos: tipo de alimentos utilizados como ração dada ao gado (por exemplo a palma), clima (quente e seco durante o dia e temperatura amena a noite), altitude entre outras. Quanto ao queijo de coalho e de manteiga feito na região estão definidas na forma de fazer como uma tradição e ao mesmo tempo tendo como insumos a matéria prima produzida na região e seus aspectos culturais. Daí a necessidade de realizar um estudo histórico geográfico e antropológico 
da tradição da produção e dos aspectos biológicos e alimentares dos produtos ofertados e seus diferenciais em relação aos das demais regiões.

\section{Modelo proposto}

Diante do que foi observado e constatado, percebeu-se que no aglomerado da pequena indústria de leite e o seu desdobramento industrial representado pelo setor de laticínios, em sua maioria, apresenta limitada capacidade instalada de processamento, baixo nível de inovação e pouco dinamismo, fatos esses que constituem impedimento ao crescimento da produção de leite e de seus derivados. Esses fatos trouxeram a perspectiva de desenvolver o modelo baseado de processo de inovação aberta (Figura 3).

Esse modelo visa contribuir para o desenvolvimento do setor estudado, introduzindo a inovação como fator estratégico de desenvolvimento no aglomerado da pequena indústria de leite na região do semiárido do Estado de Pernambuco apoiando-se no modelo de uma Indicação Geográfica (IG). E dessa forma buscando estabelecer as condições necessárias iniciais.

Figura 3

Modelo analítico Articulador de Inovação Aberta

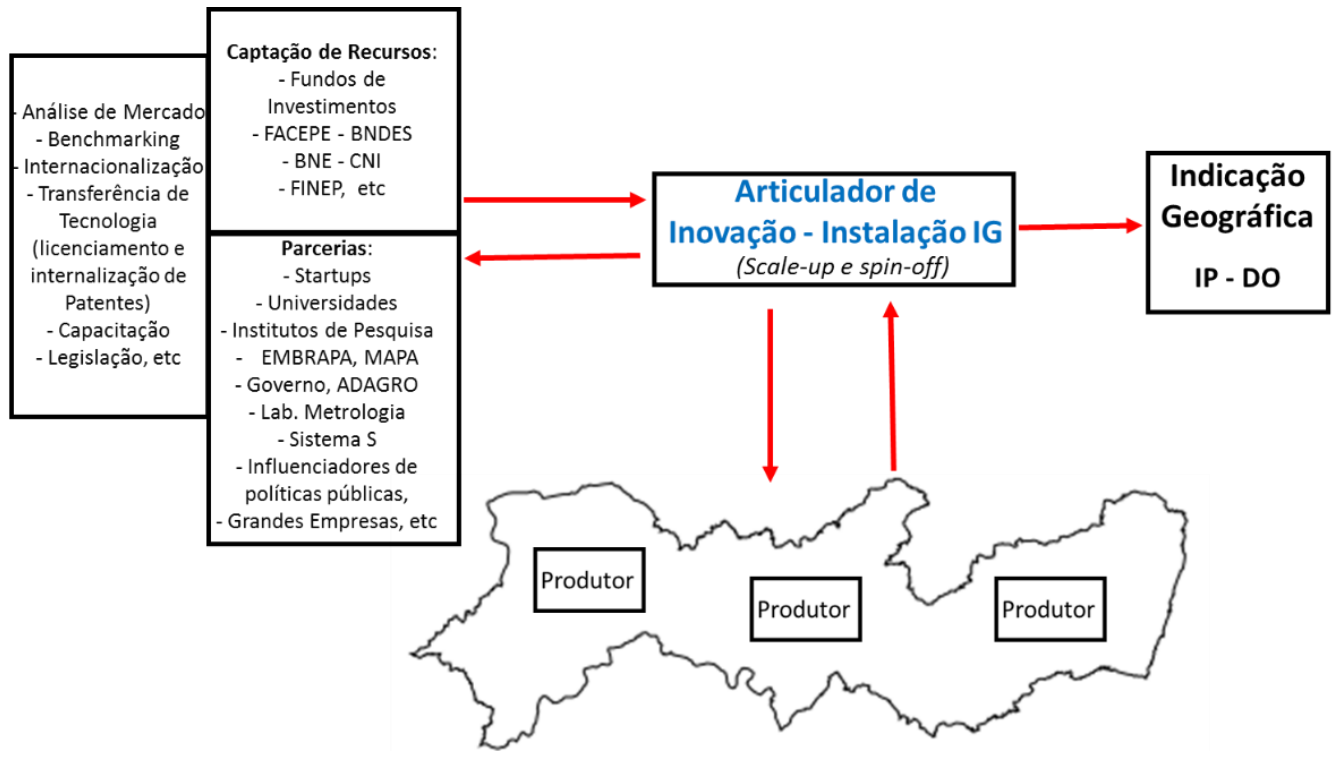

Fonte: Os autores.

O modelo proposto foi idealizado a partir dos fundamentos da inovação aberta de Chesbrough (2003), mas com foco em um processo comum para o estabelecimento das condições iniciais previstas para implantar uma IG. Ou seja, toda a estrutura essencial para a viabilidade e sucesso do modelo proposto seria construído e definido por meio de um agente externo as empresas e em conjunto com 
elas, o que seria chamado "articulador para instalação da IG" que são os membros que compunham a organização da IG, que atuaria como uma extensão ou departamento das organizações, realizando todas as atividades inerentes a um núcleo de inovação, interagindo com todo o ecossistema da indústria do leite para atender as necessidades e expectativas dos produtores e do mercado, ampliando as possibilidades de resultados, como por exemplo, a entrada de produtos novos no portfólio das empresas como queijo de coalho, manteiga e o próprio leite cru, com a melhoria de design de embalagens, divulgação da marca e a consequente expansão de mercado além das garantias de atendimento aos aspectos regulatórios para produção e comercialização desses produtos.

Como premissas básicas para o seu eficaz funcionamento, o modelo seria sistêmico e contínuo no que diz respeito ao processo ou método de aprendizagem a partir das transferências de tecnologias realizadas, teria um ambiente propício a inovação, por ser preparador, estimulador e disseminador de inovação, reconheceria como elemento fundamental para inovação as pessoas e atuaria ou trabalharia em função e para as empresas do aglomerado.

\section{Conclusão}

A partir de um diálogo com alguns produtores rurais no aglomerado da pequena indústria do leite no Estado de Pernambuco, foi possível analisar e constatar a ausência de gestão de processo de inovação aberta na região, e perceber a magnitude desse setor para economia da localidade. Por ser uma atividade tradicional onde há de fato expertise dos produtores e demanda crescente por leite e derivados, o emprego da gestão de processo de inovação aberta traria benefícios ao aglomerado da pequena indústria de leite, tendo em vista as imensas transformações ocorridas no cenário político, econômico, mercadológico e, principalmente, tecnológico, fatos esses que levaria a atividade leiteira, bem como toda a sua cadeia produtiva, a alcançarem novas fatias de mercado, tanto nacional como internacional, aproveitando concretamente o grande potencial de expansão ainda não explorado.

Apesar do número reduzido de participantes, mas pelo volume de produção de leite apresentado pelas empresas respondentes deste estudo, os dados parecem confirmar que os resultados encontrados são expressivos, e que há uma boa representatividade na produção leiteira apresentada, até por terem participado deste estudo as pequenas empresas que mais produzem leite na regional da ADAGRO do município ora estudado.

Ressaltando a importância da implantação de um modelo de gestão de processo de inovação aberta, que pode ser fomentador e organizador da produção de leite e seus derivados com mais qualidade e quantidade, impulsionando a economia da região. Também traria benefícios ao setor por ter sido constatado necessidades estruturais apontadas nos critérios considerados essenciais para o 
desenvolvimento do segmento estudado, que além do percebido necessita de um reposicionamento mercadológico para seu franco crescimento e consolidação.

\section{Referências}

Agência de Defesa e Fiscalização Agropecuária de Pernambuco. Missão. Recife, (2019). Disponível em: https://www.adagro.pe.gov.br/. Recuperado em: 19 nov. 2018.

Associação Brasileira das Indústrias de Alimentação. (2017). Disponível em: https://www.abia.org.br/vsn/temp/z201843relatorioABIA2017.pdf. Recuperado: 30 jan. 2019.

Berkhout, A. J., Hartmann, D., Van Der Duin, P., \& Ortt, R. (2006). Innovating the innovation process. International journal of technology management, 34(3-4), 390-404.

Bezerra, J. D. C., \& do Nascimento Júnior, J. R. S. (2015). A Indicação Geográfica (IG) sob o ponto de vista Geográfico para o Queijo de Coalho do Agreste de Pernambuco. Revista do Instituto de Laticínios Cândido Tstes, 70(6), 326-337.

Cerdan, C., Bruch, L., \& Lima da Silva, A. (2010). Curso de propriedade intelectual e inovação no agronegócio: modulo II. Indicação geografica.

Chesbrough, H., Vanhaverbeke, W., \& West, J. (2017). Novas fronteiras em inovação aberta. Editora Blucher.

Chesbrough, H. W. (2003). Open innovation: The new imperative for creating and profiting from technology. Harvard Business Press.

Chimento, M. R., \& de Moraes Valente, L. R. R. (2016). Indicação geográfica na mídia: o desafio da simplificação do tema para a opinião pública. Comunicação \& Sociedade, 38(3), 113-136.

Clark, K. B., \& Wheelwright, S. C. (1992). Structuring the development funnel. Revolutionizing Product Development: Quantum Leaps in Speed, Efficiency, and Quality, Cap, 5, 111-132.

Cooper Robert, G. (1993). Winning at New Products. Accelerating the Process from Idea to Launch.

Cooper, R. G. (1994). Perspective-3rd-Generation New Product Processes. Journal of product innovation management, 11(1), 3-14.

Cooper, R. G. (2008). Perspective: The Stage-Gate (R) idea-tolaunch process-update, what's new, and NexGen systems. Journal of Product Innovation Management, v. 25, n. 3, p. 213-232. https://doi.org/10.1111/j.1540-5885.2008.00296.x

de Sá, A. S. C., Novais, S. M., da Silva Nogueira, P., \& da Silva, E. S. B. (2019). Legislação e Programas ao Desenvolvimento às Indicações Geográficas no Brasil. Cadernos de Prospecção, 12(3), 706.

Decreto n. 1.355 de 30 de dezembro de 1994. (1994). Promulgo a Ata Final que Incorpora os Resultados da Rodada Uruguai de Negociações Comerciais Multilaterais do GATT. Disponível em: http://www.planalto.gov.br/ccivil_03/Decreto/Antigos/D1355.htm Recuperado em: 05 de jan. de 2019.

Demo, P. (2015). Metodologia do Conhecimento Científico. 1. ed. São Paulo: Editora Atlas. 
Fávero, K. C. Indicações geográficas como instrumento de proteção dos conhecimentos tradicionais.

Gil, Antônio. C. Como elaborar projetos de pesquisa. 4. ed. São Paulo: Atlas, 2002. 176 p.

Hill, M. M.; Hill, A. (2009). Investigação por questionário. Lisboa: Edições Sílabo, Lda, 2ạ Edição.

Instituto Brasileiro de Geografia e Estatística. (2006). Censo agropecuário 2006. Rio de Janeiro.

Instituto Nacional de Propriedade Industrial. (2018). Indicações de Procedência e Denominações de Origem reconhecidas. Disponível em: https://www.gov.br/inpi/pt-br/servicos/indicacoesgeograficas. Recuperado em: fev.2018.

Lei n. 9.279 de 14 de maio de 1996. (1996). Regula direitos e obrigações relativos a propriedade industrial, e dá outras providências. Diário Oficial da União.

Ministério da Agricultura, Pecuária e Abastecimento. (2019). Indicação geográfica e marcas: valorizando origem, qualidade e tradição. Brasília: MAPA.

Organização para a Cooperação e Desenvolvimento Econômico /Eurostat. (2018). Oslo Manual 2018: Guidelines for Collecting, Reporting and Using Data on Innovation, 4th Edition, The Measurement of Scientific, Technological and Innovation Activities, OECD Publishing, Paris/Eurostat, Luxembourg. https://doi.org/10.1787/9789264304604-en

Paquereau, B., Machado, G., \& Carvalho, S. (2016). A produção do leite e do queijo se torna cultura. Paquereau, B., Machado, G., \& Carvalho, S O queijo de coalho em Pernambuco: histórias e memórias. Garanhuns: E. dos Autores, 20-27.

Ramos, J. E. S., da Costa Borba, M., de Carvalho, D. M., \& Xavier, L. (2018). F. Eficiência técnica e desempenho econômico de produtores de leite no Agreste Pernambucano Technical efficiency and economic performance of dairy farmers' in the Agreste region of Pernambuco.

Rothwell, Roy. (1994). Towards the Fifth-Generation Innovation Process. International Marketing Review. Sussex, MCB University Press. v. 11, n. 1, p. 7-31.

Serviço Brasileiro de Apoio às Micro e Pequenas Empresas. (2013). Cenários para o leite e derivados na Região Nordeste em 2020. Recuperado em: 12 fevereiro de 2020.

https://www.sebrae.com.br/Sebrae/Portal\%20Sebrae/Anexos/estudo-Cenarios-para-leitee\%20derivados-NE.pdf

West, J., \& Bogers, M. (2017). Open innovation: current status and research opportunities. Innovation, 19(1), 43-50.

Serviço Brasileiro de Apoio às Micro e Pequenas Empresas. (2014). Indicações geográficas. Brasília: SEBRAE. Recuperado em: 30 janeiro de 2019. https://bibliotecas.sebrae.com.br/chronus/ARQUIVOS_CHRONUS/bds/bds.nsf/efd536dd061f2 a77843198d35a69265d/\$File/5186.pdf 